\title{
Circuit
}

Musiques contemporaines

\section{New Ground with Esprit Orchestra}

\section{Christien Ledroit}

Volume 13, numéro 3, 2003

Électroacoustique : nouvelles utopies

URI : https://id.erudit.org/iderudit/902291ar

DOI : https://doi.org/10.7202/902291ar

Aller au sommaire du numéro

Éditeur(s)

Les Presses de l'Université de Montréal

ISSN

1183-1693 (imprimé)

1488-9692 (numérique)

Découvrir la revue

Citer cet article

Ledroit, C. (2003). New Ground with Esprit Orchestra. Circuit, 13(3), 109-116.

https://doi.org/10.7202/902291ar

Ce document est protégé par la loi sur le droit d'auteur. L'utilisation des services d'Érudit (y compris la reproduction) est assujettie à sa politique d'utilisation que vous pouvez consulter en ligne.

https://apropos.erudit.org/fr/usagers/politique-dutilisation/
Cet article est diffusé et préservé par Érudit.

Érudit est un consortium interuniversitaire sans but lucratif composé de l'Université de Montréal, l'Université Laval et l'Université du Québec à Montréal. Il a pour mission la promotion et la valorisation de la recherche. https://www.erudit.org/fr/ 


\title{
New Ground with Esprit Orchestra
}

\author{
Christien Ledroit
}

On March 30, 2003, Toronto's Esprit Orchestra performed a concert which included two works by young Canadian composers, Brian Current's Kazabazua and Yannick Plamondon's concerto for piano Stark, Utter, Forego... (also included in the program was Wolfgang Rihm's Time Chant with violinist Marie Bérard). Each of these in its own way makes great demands on the performers, and clearly justify such demands. Alex Pauk, Esprit's music director and conductor, chose these two young composers because they are emerging as important creative forces within the Canadian new music scene.

The concert was preceded by an informal lecture/Q\&A with the composers, hosted by Alexina Lovie. Both Current and Plamondon took time to explain as much about these pieces as time permitted, and fielded questions from the audience. This discussion provided the composers with an opportunity to expand upon the notes included in the program, and discuss in somewhat greater depth some of the more interesting and intricate aspects of their works.

The first work on the program was Brian Current's Kazabazua. The title of this piece refers to a small town in Quebec where much of the piece was composed. Kazabazua is an Algonquin term meaning "disappearing waters". It refers to a natural phenomenon which occurs at the town, whereby the water of the river disappears underneath the earth at one side of the town only to reappear at the other side. Current uses the analogy of the river at Kazabazua throughout the work, but most obviously in his musical direction at the end of the first movement. A note in the score under the last bar reads "about 5 seconds between the movements; complete silence as if the music is still going on under the silence and then emerges on the other side in part II".

Current began his pre-concert talk by referring to a sense of relentlessness in his music. This was evident from the outset of the work, which begins with low strings in frantic short bursts. The opening instruction in the score reads "filled with energy, unstoppable". Fortunately, the orchestra was up to the challenge. 
These short gestures are early hints at what Current referred to as being "violent shakes" of sound and colour. Current discussed an attempt at turning the instruments of the orchestra into one large shaker-like percussion instrument; this process begins in the first bar with these figures. Quickly other instruments are added, creating a more robust sound, and giving added timbral interest to what might otherwise risk becoming monochromatic and repetitive. This is typical of the attention to textural and colouristic detail evident throughout this work.

Much of this piece has individual sections of the strings divided, sometimes into as much as six parts. This is necessary because of what Current refers to as "impossible lines". The composer is trying to push the boundaries of instrumental possibility, and thus has several players share a phrase that would be otherwise unplayable: each group of performers plays a short segment of a phrase, which is immediately picked up by the next group. As a result, the overall texture is frequently one of chamber music, since throughout much of the work only a part of any given section is actually playing.

Current also referred to "flipping" the sound of a maraca with the orchestra. He was trying to start with a shaker sound, then add the orchestra on top of that, in effect turning the orchestra into a large percussion instrument. This is clearly attempted in several different ways throughout the first movement of this work, with varying degrees of success. Interesting textures abound, but never does one sense that the entire orchestra, or even sections of the orchestra, acoustic properties of a shaker sound, - extremely high attack density over a short period of time, with relatively little (though at least some) variation in pitch - has transposed these properties to the strings. This explains string figures in the first minute of the work, which gradually move up and down in register through short whole-tone or similar configurations.

These figures frequently build and seem to explode into a descending floating gesture which adds a sharp contrast to the texture and overall mood of the work. One has the sense of small bits of shrapnel floating to the ground after a small explosion each time this motif occurs. It almost has a slight cartoon-ish feel, but always avoids triviality or affectation.

Another interesting textural effect found in this movement occurs about half way through: Current refers to it as a "flanging" sound, which is a perfect description of this string texture. It consists of dense chords played staccato, starting in the low strings and rising quickly, growing progressively more dense towards the highest registers of the violins (necessitating harmonics), to chromatic clusters, then descending again (example 1).

This is a spectacular texture, and very much resembles a 'flange' sound, as it mimics the frequency sweep of the popular studio effect. The interplay here between the percussion and the strings is also quite peculiar. The percussionist shakes a rain stick, as one would shake a maraca. These shakes get louder as the strings ascend, and softer as the strings descend, until they stop altogether. It is as if the flanging effect, as played by the strings, were being applied to the source sound of the percussion. 
Example 1 : Kazabazua, movement 1, m. 205-209, reduction.
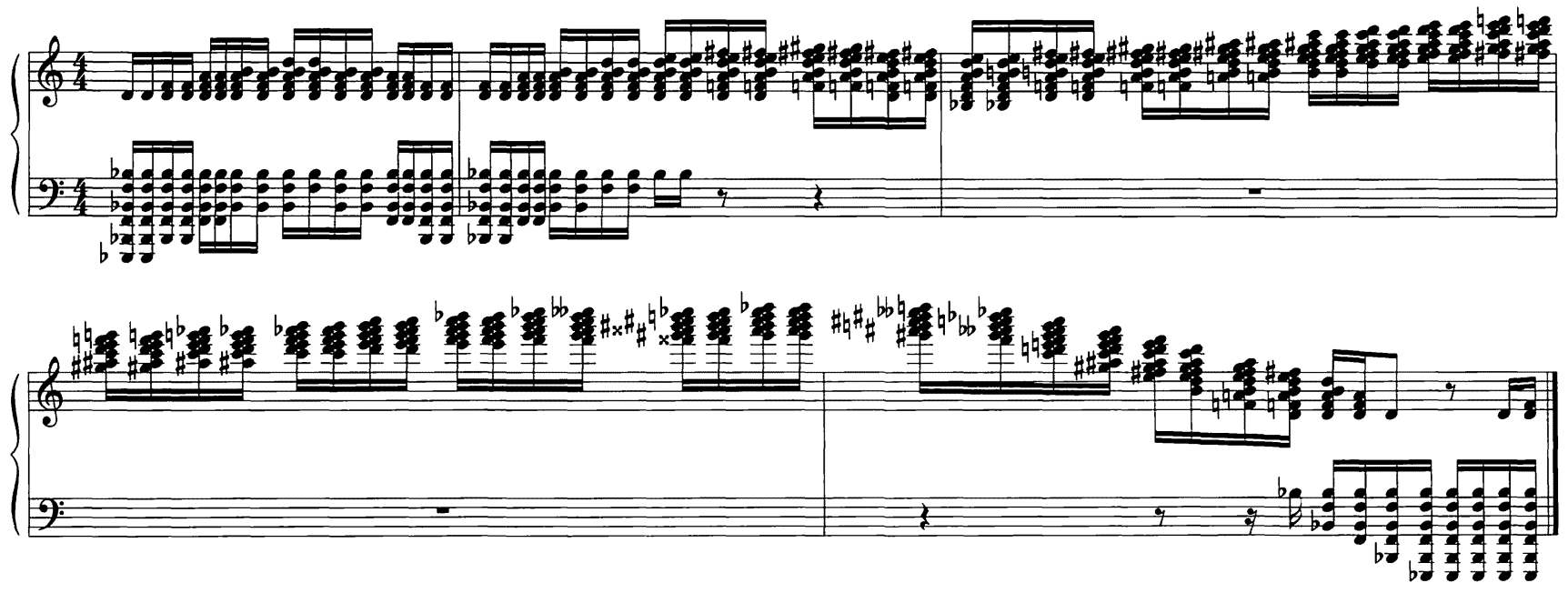

The second movement of this work, while not leaving behind the textural emphasis of the first, focuses on a completely different aspect, that of accelerando. Current explained that his goal in this movement was to treat the state of accelerando as the normal existing state of the music; that is, the music is always increasing in tempo. He refers to this technique as composing music in "slanted time". This occupies substantial sections of the movement. A continuous accelerando would of course get out of hand rather quickly, had the composer not included metric modulations every four measures during these passages. Simply stated, this process involves increasing the tempo significantly (usually at least doubling) over four measures, then immediately culting the tempo in half. At the moment the tempo is halved, slower rhythms lquarter- and eighth-notes) are doubled such that they sound exactly the same as before the meter change, and faster rhythms (sixteenth-notes) become tremolos, to quickly fade away. The faster notes are faded out and replaced with slower rhythms (half the note values) fading in, which also sound the same as before the meter change. This is clearly visible in the score (example 2).

While Current did not mention it, this constant acceleration with metric modulations is clearly a rhythmic counterpart to the pitch phenomenon known as Shepard tones, whereby rising or lowering frequencies are replaced as they near their registral limits with lower or higher pitches, creating the illusion of an infinitely rising or lowering pitch or scale.

The composer describes the purpose of this process as allowing the music to constantly renew itself, as the gestures quicken into a blur (very quick rhythms or tremolos) and quickly disappear, just as a new gesture is being introduced. While not explicitly mentioned by the composer, the analogy here to water and the flowing of a river is clear. The analogy works not only in theoretical terms, but also sonically; 
Example 2: Kazabazua, movement 2, m. 117-121, full score (strings omitted). An accelerando from $q=80$ begins in $\mathrm{m}$. 115. The accelerando beginning in $\mathrm{m} .119$ speeds to $\mathrm{q}=160$ in $\mathrm{m} .122$.

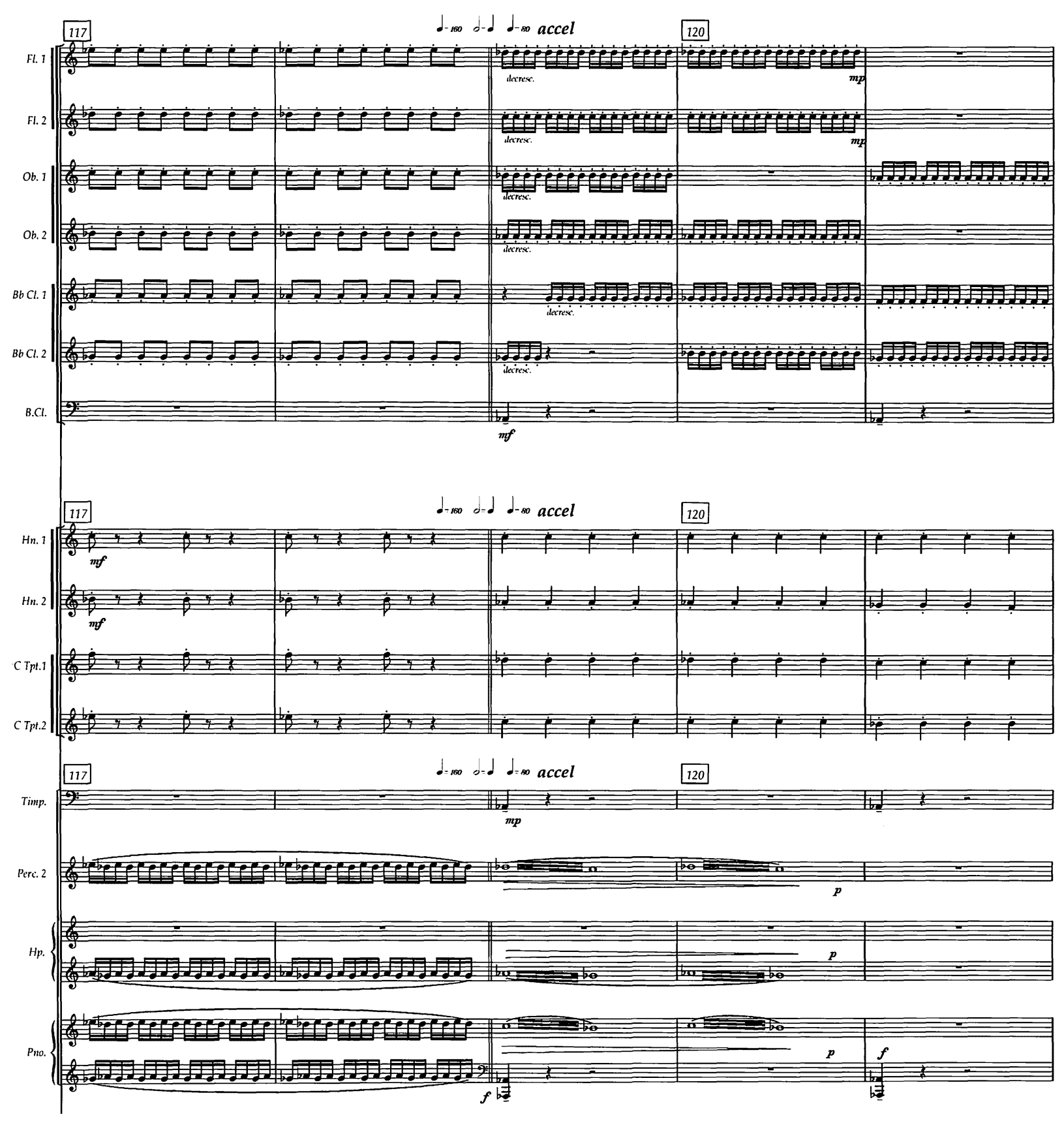


the listener clearly senses the constant accelerando. It's a shame that the orchestration is not denser during these passages, which would have conveyed the sense of gradual acceleration much more imperceptibly. As it is, this process is carried out with minimal forces, and often the metric modulations are even emphasized with changes of pitches and harmonies. Perhaps the composer intends these modulations to be noticed, despite the fact that the concept of "slanted time" seems to lend itself more to the imperceptibility inherent in Shepard tones.

A powerhouse of textural variety and innovative composing, Kazabazua convinces even when Current's stated objectives are only partly realized, and it rewards repeat listening.

The closing piece on the program was Yannick Plamondon's piano concerto, Stark, Utter, Forego, dedicated to the American author Russell Banks. This work is an extremely demanding work, not only for the soloist, but also for the orchestra. The soloist for this work was Marc Couroux, who handled the performance brilliantly. Couroux is perhaps one of the most talented young performers of contemporary music in Canada today. He combines stellar technique with an unusually deep knowledge of the works he performs, which is no doubt helped by the fact that Couroux is also a composer. It was an unusual treat to see him in a performance such as this.

In his brief notes to the piece, Plamondon suggests some of the broader concepts around which the work is based: consciousness of the process of composing, the complex relations between truth and fiction, organization of lines moving in and out of the main conceptual frame, and lines contained within their own complexity. These are of course reflected throughout the score, but sometimes less than clearly, and always in unusual ways. In his discussion of this piece, Plamondon said that the three words in the title describe the atmosphere of each respective movement.

Perhaps the most striking aspect of this piece is its lack of variety, normally a shortcoming, but here a minimum of material is clearly deliberate and fully exploited. For example, most of this work is written at least mezzo-forte or louder, with very little variety of tempo or texture. By the end of the piece the listener is exhausted, having been assailed by twenty-five minutes of intense, intricate and loud music. Relentlessness is a key aspect of the piece, as in Current's Kazabazua, but is accomplished through much more direct means.

The title of the first movement, "Stark", naturally creates certain textural expectations. These expectations are quickly thwarted, and we learn from the program notes that 'Stark' refers not to the adjective, but to the title character of Russell Banks' novel Hamilton Stark, in which, according to Plamondon, "loneliness [is] considered as [a] heroic, but also suspicious representation of passion and wisdom". Plamondon problematizes the relationship of the soloist to the orchestra in terms of the nineteenth century paradigm of the soloist as hero. Questioning the concept of the hero in the contemporary world, he avoids setting his soloist in opposition to the 
orchestra. He views the soloist sociologically as an individual within society (the orchestra). Furthermore, he envisions society as being composed of several subgroups, each representing different aspects of a person's individuality. This is reflected consistently throughout the score in the way instruments are grouped with similar material, and also in the way the piano is frequently doubled by other instruments (most frequently the vibraphone).

The second movement, "Utter", is the shortest of the three. This movement seems to operate in two parts, with the second part gradually returning to the materials of the first part. Curiously, the first movement ended with a rallentando then an accelerando, which is somewhat striking as it is the only tempo change in the first movement. The first part of the second movement mirrors this slowing down then speeding up of tempo. The materials are divided between the strings, winds and percussion, with each section having more or less its own figures and gestures. The piano tends to move back and forth between the materials of each section, composing its line from fragments of the phrases from these groups. This, or course, is in keeping with the sociological model which underpins the work (example 3).

The third movement of this concerto, "Forego", is in some ways the most interesting, even though on the face of it, the simplest: it contains a fair amount of reminiscences of material from the previous movements, and, most unusually, the piano part, written as a very simple line, continues similarly throughout almost the entire movement, doubled with vibraphone (example 4).

The composer tells us that the title refers to the renunciation of a prerogative, in this case the composing of a cadenza. Instead, the creation of the cadenza is shared with the soloist. The basic material of the cadenza is pre-recorded bits of music played back by the pianist. Prior to the concert, the composer and performer met to record the piano parts of the first two movements. This recording was broken up into smaller chunks of phrases and gestures, and loaded into a computer. These short sounds were then triggered during the performance by the pianist, using a midi keyboard patched into the computer. There are no written instructions in the score as to which sounds should be played back, or in what order; the choice is completely up to the performer. The composer explained that this was his version of a cadenza; not only does it recall materials from the work, but because the performer is able to trigger several notes by depressing only one key land exponentially more by depressing a cluster of keys), the effect is quite virtuosic.

Plamondon speaks of the importance of his choice of performer for this work. The pianist must fully comprehend the work, and be able to make informed decisions as to the improvisation of these pre-recorded sounds. He explained that because Couroux is not only an excellent performer but also a skillful composer, he was an ideal choice for the work.

At the conclusion of this piece, one is left with a sense of fatigue. Because of the extreme lack of variety, one is subjected to similar materials for over twenty-five 
Example 3: Stark, Utter, Forego, movement 2, "Utter", m. 186-189, showing piano drawing its materials from winds' and strings' materials.

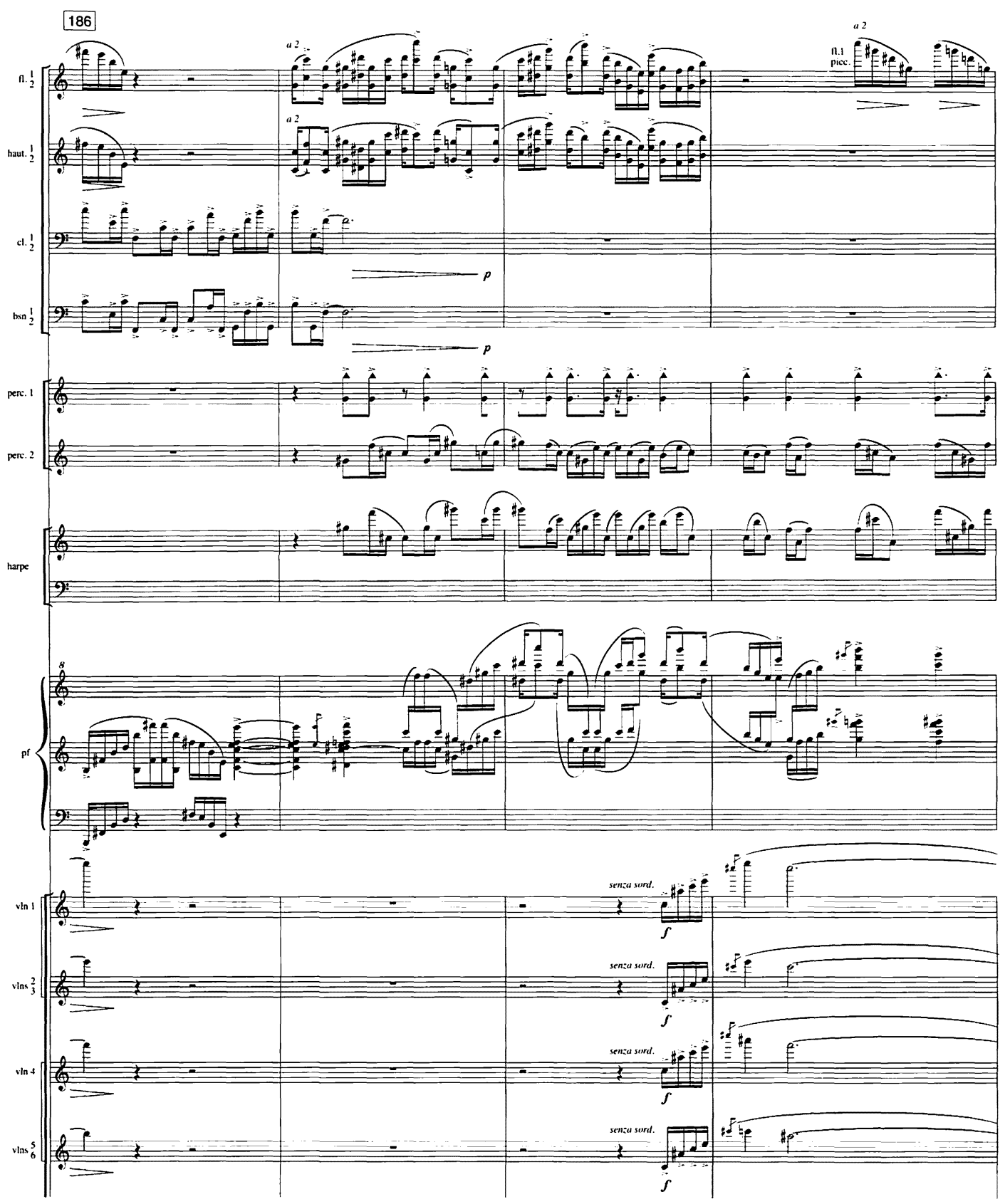


Example 4: Stark, Utter, Forego, movement 3, "Forego", m. 412-419, percussion 2 (vibraphone) and piano.

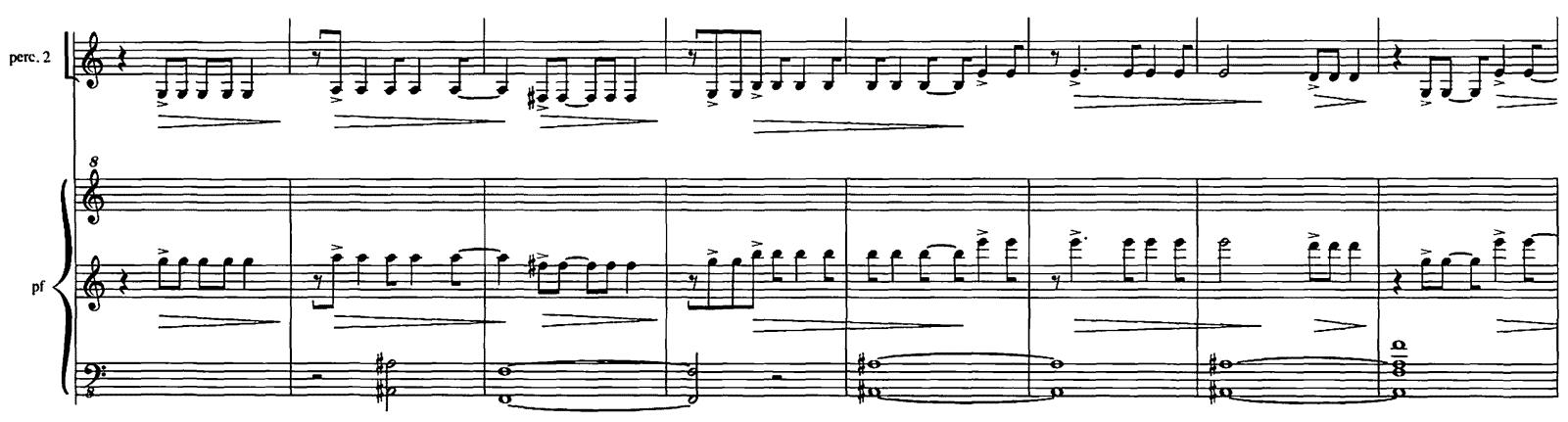

minutes. But rather than tedium, the piece leaves us with a sense of wanting more (though in no way giving the sense of incompleteness), and the conviction that the piece is a success.

The Esprit Orchestra offered an evening in the company of two composers who are pushing their creative senses through excursions into new musical territory, each in his own way, each quite successful in their ventures. The orchestra performed these pieces with apparent ease, which is no mean feat. The Esprit Orchestra proves itself once again with rich works full of stimulating ideas, of the musical and philosophical varieties. 